\title{
STRESS DEGRADATION STUDIES OF RAMIPRIL BY A VALIDATED STABILITY-INDICATING LIQUID CHROMATOGRAPHIC METHOD
}

\author{
M. DE DIEGO*, G. GODOY, S. MENNICKENT, M. OLIVARES, R. GODOY.
}

University of Concepción, Pharmacy Department, Pharmacy School, PO Box 237, Concepción, Chile. (Received: September 15, 2010 - Accepted: November 19, 2010)

\begin{abstract}
Ramipril is an angiotensin-converting enzyme inhibitor which has chemical structure susceptible to degradation, therefore in this work forced degradation studies of ramipril were carried out by a developed and validated stability-indicating liquid chromatographic method. Stress testing was performed on drug substance under hydrolysis $(0.1 \mathrm{~N} \mathrm{HCl}$, water and $0.1 \mathrm{~N} \mathrm{NaOH})$, oxidation $\left(3 \% \mathrm{H}_{2} \mathrm{O}_{2}\right)$, heat $\left(70^{\circ} \mathrm{C}\right)$ and photolysis (UV and VIS radiation). The drug was degraded under acidic, neutral, alkaline, oxidation and thermal stress conditions but it was stable under photolysis. Chromatographic separation of ramipril from its degradation products was achieved on a RP-18 column, using a mobile phase consisting of methanol - tetrahydrofuran - phosphate buffer (pH 2.4; $0.01 \mathrm{M}$ ) $(55: 5: 40, \mathrm{v} / \mathrm{v} / \mathrm{v})$ at a flow rate of $1.0 \mathrm{~mL} \mathrm{~min}{ }^{-1}$ and $\mathrm{UV}$ detection at $215 \mathrm{~nm}$. The assay was linear for ramipril concentrations of $50-300 \mu \mathrm{g} / \mathrm{mL}$. The developed method was stability indicating, specific, accurate and precise for ramipril determination. This method was used to quantify ramipril in tablets. The results showed that the method described here is suitable for quantitative determination and the stability study of ramipril.
\end{abstract}

Keywords: Stress testing, stability-indicating, ramipril, drug substance, tablets.

\section{INTRODUCTION}

Stability testing is an important part of drug development process; it provides evidence on how the quality of drug substance or drug product varies with time under the influence of a variety of environmental factors, such as temperature, humidity, and light ${ }^{1}$. The objective of the stress testing is to anticipate the behaviour of the drug substance when using it as a drug product. Stress testing of the drug substance can help identify the likely degradation products, which can in turn help to establish the degradation pathways and the intrinsic stability of the molecule and developed stability-indicating analytical methods. The nature of the stress testing will depend on the individual drug substance and the type of drug product involved ${ }^{1,2}$.

Ramipril (Fig. 1) is an angiotensin-converting enzyme (ACE) inhibitor used in the management of mild to severe hypertension. It is a prodrug which after absorption, undergo rapid metabolism by ester hydrolysis to the active diacidic form ramiprilat [3]. Due to the presence of the ester group it is highly susceptible to undergo degradation.

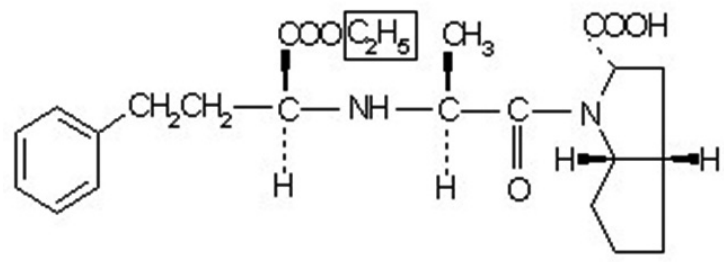

Figure 1. Chemical structure of ramipril. The structure enclosed within box is replaced with a hydrogen atom to form the active molecule in vivo (ramiprilat).

There are few works related with stability studies of ramipril: stress studies for the simultaneous determination of ramipril/moexipril ${ }^{4}$, ramipril/ telmisartan ${ }^{5}$, and ramipril/hydrochlorothiazide ${ }^{6}$, a forced degradation study of ramipril in Altace ${ }^{\circledR}$ capsules $^{7}$, a stability study of ramipril at different $\mathrm{pH}^{8}$, a study of stability of ramipril over time in water apple juice and applesauce 9 , and a comparative study of stability over time of marketed ramipril generics tablets versus reference ramipril tablets ${ }^{10}$. There are other works described in the literature but for the determination of ramipril and ramiprilat in biological samples ${ }^{11,12}$.

In order to obtain the complete stability characteristics of ramipril, the objectives of this study were (1) to develop and validate a simple stabilityindicating LC method for ramipril quantification and (2) to determine the chemical stability of ramipril drug substance under various ICH (International Conference on Harmonization) stress testing.

\section{EXPERIMENTAL}

Chemicals and reagents

Standard of ramipril, cloxacillin sodium and ramipril diketopiperazine were obtained from USP (Rockville, MD, USA). Methanol and tetrahydrofuran LC grade, $\mathrm{KH}_{2} \mathrm{PO}_{4}$, sodium hydroxide, hydrochloric acid and hydrogen peroxide p.a. grade were obtained from Merck (Darmstadt, Germany). Ramipril drug substance was obtained from Pasteur Pharmaceutical (Concepción, Chile). Two commercial products of ramipril tablets $2,5 \mathrm{mg}$ were purchased from a Chilean pharmacy (both with expiration date in December 2010).

\section{Instrumentation and chromatographic conditions}

Chromatography was performed by using a Perkin Elmer Series 200 liquid chromatograph (Norwalk, CT, USA) equipped with a manual injector, a 7125 Rheodyne injection valve (Cotati, CA, USA), and a $20-\mu \mathrm{L}$ loop. An Applied Biosystems Model 785A programmable absorbance detector (Foster, CA, USA), and a Perkin Elmer Nelson Model 1022 data processor (Norwalk, CT, USA).

All analyses were performed at room temperature $\left(23 \pm 2{ }^{\circ} \mathrm{C}\right)$ under isocratic conditions. The separation was carried out using a Purospher ${ }^{\circledR}$ RP-18 column (150 mm x $4.6 \mathrm{~mm}, 5 \mu \mathrm{m}$; Merck, Darmstadt, Germany). The mobile phase consisted of methanol - tetrahydrofuran - phosphate buffer ( $\mathrm{pH}$ 2.4; $0.01 \mathrm{M})(55: 5: 40, \mathrm{v} / \mathrm{v} / \mathrm{v})$. The UV detection was made at $215 \mathrm{~nm}$ and the flow rate was $1.0 \mathrm{~mL} / \mathrm{min}$. Cloxacillin sodium $(125 \mu \mathrm{g} / \mathrm{mL})$ was used as the internal standard.

Preparation of standard solutions

A stock solution of ramipril and a stock solution of cloxacillin sodium were independently prepared at about $2.5 \mathrm{mg} / \mathrm{mL}$ and $3.0 \mathrm{mg} / \mathrm{mL}$ respectively in methanol. Standard solutions were prepared from the stock solution after adequate dilution with water. A stock solution of ramipril diketopiperazine was prepared at $1 \mathrm{mg} / \mathrm{mL}$ in methanol.

\section{Preparation of sample}

10 tablets of ramipril $2,5 \mathrm{mg}$ were weighed and powered. A portion equivalent to $5 \mathrm{mg}$ of ramipril was accurately weighed and transferred to a 25 $\mathrm{mL}$ volumetric flask, then $20 \mathrm{~mL}$ of methanol:water $(55: 45, \mathrm{v} / \mathrm{v})$ and a portion of $1 \mathrm{~mL}$ of internal standard $(3,1 \mathrm{mg} / \mathrm{mL})$ were added. The solution was sonicated for 10 minutes and the volume was made up with methanol:water $(55: 45$, $\mathrm{v} / \mathrm{v}$ ) (final concentration of $200.0 \mu \mathrm{g} / \mathrm{mL}$ ), the mixture was vortexed for $15 \mathrm{~s}$, filtered and centrifuged for $5 \mathrm{~min}$, and the supernatant was chromatographed.

Stability-indicating capability of the LC assay 
It was established by chromatographic analysis of all stressed samples (as explained in section stress testing). The composition, $\mathrm{pH}$ and the flow rate of the mobile phase were modified to optimize separation between ramipril, degradation products and the internal standard.

\section{Method validation}

The method was validated according to the ICH guidelines for validation of analytical procedures ${ }^{13}$. The parameters validated were linearity, precision, accuracy, selectivity, robustness, detection and quantitation limits, and stability of standard solution.

\section{Stress testing}

Stress testing was carried out according to the ICH stability testing guidance ${ }^{1}$. Ramipril was stressed under various conditions until to facilitate approximate $5-20 \%$ degradation ${ }^{14}$. For each condition, a blank solution was prepared and was subjected to stress in the same manner as the drug, also a control solution of ramipril was prepared, which was stored without the stress condition.

a) Hydrolysis acidic, neutral and alkaline:

A solution of ramipril $10 \mathrm{mg} / \mathrm{mL}$ was prepared in methanol, then an aliquot of $2 \mathrm{~mL}$ was transferred to a $10 \mathrm{~mL}$ volumetric flask and diluted with $0.1 \mathrm{~N}$ $\mathrm{HCl}$, water and $0.1 \mathrm{~N} \mathrm{NaOH}$ to volume. Samples of $3 \mathrm{~mL}$ were kept on a hot plate at $60{ }^{\circ} \mathrm{C}$ for basic hydrolysis for $5 \mathrm{~min}$, and at $80{ }^{\circ} \mathrm{C}$ for acid and neutral hydrolysis for $30 \mathrm{~h}$. After which they have been cooled to room temperature, then the samples were transferred to a $25 \mathrm{~mL}$ volumetric flask, neutralized, a $1 \mathrm{~mL}$ of internal standard $(3.1 \mathrm{mg} / \mathrm{mL})$ was added, and they were diluted to volume.

\section{b) Oxidation:}

A solution of ramipril $10 \mathrm{mg} / \mathrm{mL}$ was prepared in methanol, then an aliquot of $2 \mathrm{~mL}$ was transferred to a $10 \mathrm{~mL}$ volumetric flask and diluted with $3 \% \mathrm{H}_{2} \mathrm{O}_{2}$ Samples of $3 \mathrm{~mL}$ were kept on a hot plate at $80^{\circ} \mathrm{C}$ for $6 \mathrm{~h}$ and at room temperature $\left(25 \pm 2^{\circ} \mathrm{C}\right)$ for 7 days in the dark, then they were transferred to a 25 $\mathrm{mL}$ volumetric flask, a $1 \mu \mathrm{L}$ of internal standard $(3.1 \mathrm{mg} / \mathrm{mL})$ was added, and they were diluted to volume.

\section{c) Thermal degradation:}

About $50 \mathrm{mg}$ of ramipril was exposed to dry heat at $70^{\circ} \mathrm{C}$ in an oven for 21 days. Then a solution of ramipril $200 \mu \mathrm{g} / \mathrm{mL}$ with internal standard $125 \mu \mathrm{g} /$ $\mathrm{mL}$ was prepared.

\section{d) Photostability:}

An aqueous/methanolic solution of ramipril $2 \mathrm{mg} / \mathrm{mL}$ and solid drug in 1 $\mathrm{mm}$ layer in a petri-plate, were exposed to UV $(365 \mathrm{~nm})$ and VIS radiation for 8 days. Then solutions of ramipril $200 \mathrm{mg} / \mathrm{mL}$ with internal standard $125 \mathrm{mg} /$ $\mathrm{mL}$ were prepared. Dark controls were run simultaneously.

\section{RESULTS AND DISCUSSION}

\section{Stability-indicating LC method development and optimization}

The main target of the stability-indicating chromatographic method is to get the separation between ramipril and their degradation products. Some of the reported method for ramipril used gradient and/or a high column temperature, which requires more sophisticated instrumentation and/or long stabilization times $5,7,8$. In the present study different proportions of methanol $(50,55$, $60,65 \%)$ and change in $\mathrm{pH}(2.2,2.4,2.6)$ were evaluated before the final chromatographic conditions were selected. Also acetonitrile was tested instead of methanol, but peak shapes were not satisfactory. From these studies it was determined that the $\mathrm{pH}$ of the mobile phase is very important in order to avoid peak tailing. Optimal separation of ramipril, degradation products and internal standard, with sharp peaks was achieved with a methanol - tetrahydrofuran phosphate buffer $(\mathrm{pH} 2.4 ; 0.01 \mathrm{M})(55: 5: 40, \mathrm{v} / \mathrm{v} / \mathrm{v})$ mobile phase under isocratic conditions at room temperature. The evaluated system suitability parameters were: Rs 4,7 and 2,2 (between ramipril / internal standard and ramipril / ramiprilat); $a$ 1,5 and 1,3 (between ramipril / internal standard and ramipril / ramiprilat); $N 2600$ and $T$ 1,1 (for ramipril). Fig. 2 to 6 shows chromatograms of stressed samples and internal standard, which prove the stability-indicating capability of the assay.

\section{Sample preparation studies}

A study was performed in order to determine the optimum sonication time for complete leaching of the ramipril from tablets. Ramipril tablets $2,5 \mathrm{mg}$ were treated as explained in section preparation of sample, and the times of sonication evaluated were 5,10 and $15 \mathrm{~min}$. The percentage of ramipril was found to be $96,6 \pm 0,1 \%, 99,8 \pm 0,8 \%$ and $99,4 \% \pm 0,3 \%$ (mean $\pm \mathrm{SD}, \mathrm{n}=$ 6) for 5, 10 and 15 minutes of sonication respectively, therefore a 10 minutes sonication time was selected in the proposed method.

\section{Method validation}

Linearity

The calibration curve of ramipril was linear over the concentration range of 50.0 to $300.0 \mu \mathrm{g} / \mathrm{mL}$ ( 6 different concentrations were used and each solution was injected 5 times). The equation of the standard curve based on the ratio of the peak heights of ramipril / internal standard to the ramipril concentration was $y=0.0052 x+0.0404 ; \mathrm{r}^{2}=0.9955$.

\section{Precision}

The intra-day precision was determined by analysis of three different preparations in concentrations of $160.0,200.0$ and $240.0 \mu \mathrm{g} / \mathrm{mL}$ on the same day. The inter-day precision was studied by comparing the assays on three different days. The results are shown in Table 1. The obtained values show a suitable precision for the analytical method.

Table 1. Precision determined during method validation.

\begin{tabular}{|c|c|c|}
\hline \multirow{2}{*}{$\begin{array}{c}\text { Concentration } \\
(\mu \mathrm{g} / \mathrm{mL})\end{array}$} & \multicolumn{2}{|c|}{ Relative standard deviation (\%) } \\
\cline { 2 - 3 } & ${\text { intra-day }{ }^{\text {a) }}}^{\text {inter-day }}{ }^{\text {b }}$ \\
\hline 160.00 & 0.71 & 1.47 \\
\hline 200.00 & 1.39 & 1.84 \\
\hline 240.00 & 0.73 & 0.27 \\
\hline a) & Analyzed on the same day $(\mathrm{n}=3)$.
\end{tabular}

b) Analyzed on three different days $(\mathrm{n}=9)$.

Accuracy

To evaluate the accuracy of the method, recovery test were performed by adding know amounts of standard of ramipril in the level 80, 100 and $120 \%$ of the ramipril levels in the tablets (three replicates of each level) to common tablet excipients (lactose, starch and magnesium stearate). The accuracy of the assay was determined by comparing the found amount with the added amount. The results obtained are shown in Table 2. The obtained values confirm the accuracy of the proposed method.

Table 2. Recovery percentage of ramipril determined during method validation.

\begin{tabular}{|c|c|c|c|}
\hline $\begin{array}{c}\text { Sample } \\
\text { Level } \\
(\%)\end{array}$ & $\begin{array}{c}\text { Added } \\
\text { Amount } \\
(\mathrm{mg})\end{array}$ & $\begin{array}{c}\text { Found } \\
\text { Amount } \\
(\mathrm{mg})^{\mathrm{a})}\end{array}$ & $\begin{array}{c}\text { Recovery } \\
(\%)^{\mathrm{b})}\end{array}$ \\
\hline 80 & 2.00 & $2.00 \pm 0.02$ & 99.85 \\
\hline 100 & 2.50 & $2.48 \pm 0.05$ & 99.29 \\
\hline 120 & 3.00 & $2.99 \pm 0.04$ & 99.53 \\
\hline a) & Mean $\pm \mathrm{SD}(\mathrm{n}=3)$.
\end{tabular}

b)

(Found amount/ Added amount) x 100.

Selectivity

Results from the stress testing studies indicated that the method is selective towards ramipril, degradation products and internal standard as shown in Fig. 2 to 6. Cloxacillin was selected as internal standard due to its suitable retention, sharp peak and similar physicochemical properties to ramipril. The selectivity was also evaluated by observing any interference from excipients used in the tablets; therefore a sample of each commercial product was analyzed, showing no peaks that interfered with ramipril, degradation products or internal standard. These results proved the selectivity of the proposed method.

Robustness

To determine robustness of the method, variation of flow rate from 0.8 to 1.2 and the amount of organic solvent in the mobile phase from 53 to 57 $\%$ were realized and resolution between ramipril and internal standard were evaluated. At all conditions the resolution was found to be greater than 4 which proved the robustness of the method.

Detection and quantitation limits

The DL and QL were calculated by using the equations: $\mathrm{DL}=3.3 \mathrm{x} \mathrm{s} / \mathrm{S}$; $\mathrm{QL}=10 \mathrm{x} \mathrm{s} / \mathrm{S}$, where $\mathrm{s}$ is the standard deviation of the response and $\mathrm{S}$ is the slope of the calibration curve. DL was $0.24 \mu \mathrm{g} / \mathrm{mL}$ and $\mathrm{QL}$ was $0.74 \mu \mathrm{g} / \mathrm{mL}$. 
These values are adequate for the ramipril determination in pharmaceutical samples.

Stability of standard solution

The stability of the standard solution of ramipril was evaluated at room temperature $\left(23 \pm 2{ }^{\circ} \mathrm{C}\right),+8 \pm 1{ }^{\circ} \mathrm{C}$ and $-20 \pm 0.5^{\circ} \mathrm{C}$, for 3,11 and 29 days respectively. The stability was determined by comparing the concentration at each time with the initial ramipril concentration. The results indicate that the solutions were stable for 2,8 and 25 days at room temperature $\left(23 \pm 2{ }^{\circ} \mathrm{C}\right),+8 \pm$ $1{ }^{\circ} \mathrm{C}$ and $-20 \pm 0.5^{\circ} \mathrm{C}$ respectively, as there the concentration remained almost unchanged and there was no formation of degradation products.

\section{Stress testing}

a) Hydrolysis:

In all the studied stress conditions, the degradation of ramipril was higher under alkaline stress. After $5 \mathrm{~min}$. of hydrolysis in $0.1 \mathrm{~N}$ sodium hydroxide, the percentage of ramipril degradation was $34.6 \%$. It was observed the formation of one degradation product, which according to Elshanawane ${ }^{4}$ and Hanysova ${ }^{8}$, it corresponds to the diacidic form of the drug; ramiprilat. This can be observed in Fig. 2.

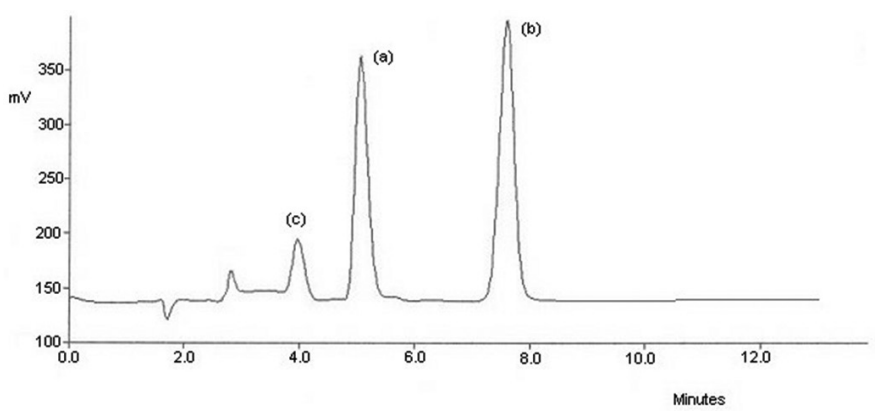

Figure. 2. Representative chromatogram of ramipril under alkaline stress: ramipril (a), cloxacillin sodium (b), ramiprilat (c). 1mV: $0.001 \mathrm{AU}$.

After $30 \mathrm{~h}$. of hydrolysis in water and $0.1 \mathrm{~N}$ hydrochloric acid, the percentage of ramipril degradation was $20.2 \%$ and $21.8 \%$ respectively. It was observed the formation of three degradation products; a degradation product with that appeared at the same retention time that the alkaline degradation product, therefore probably it corresponds to ramiprilat, a degradation product identified as ramipril diketopiperazine by comparing the chromatograms of stressed samples with chromatograms of standard solution of this compound, and a degradation product with that eluted between ramipril and internal standard. The principal degradation product for acidic hydrolysis was ramipril diketopiperazine. This can be observed in Fig. 3 and 4 . These results are different with previous work; Elshanawane ${ }^{4}$ reported the formation of only ramipril diketopiperazine in acidic hydrolysis, and $\mathrm{K}$. Patil ${ }^{5}$ reported a 0.5 $\%$ of ramipril degradation in acidic condition, and no information about identification of degradation products was reported. But, the conditions of degradation were at lower temperatures and/or for less time.

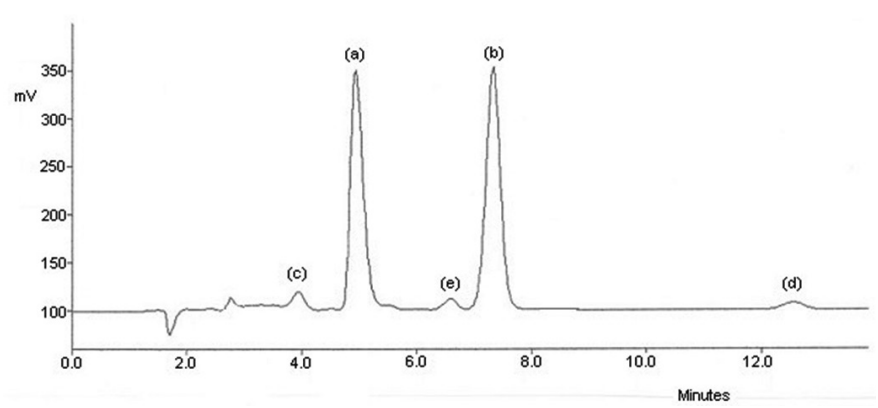

Figure. 3. Representative chromatogram of ramipril under neutral stress: ramipril (a), cloxacillin sodium (b), ramiprilat (c), ramipril diketopiperazine (d), other degradation product (e). $1 \mathrm{mV}: 0.001 \mathrm{AU}$.

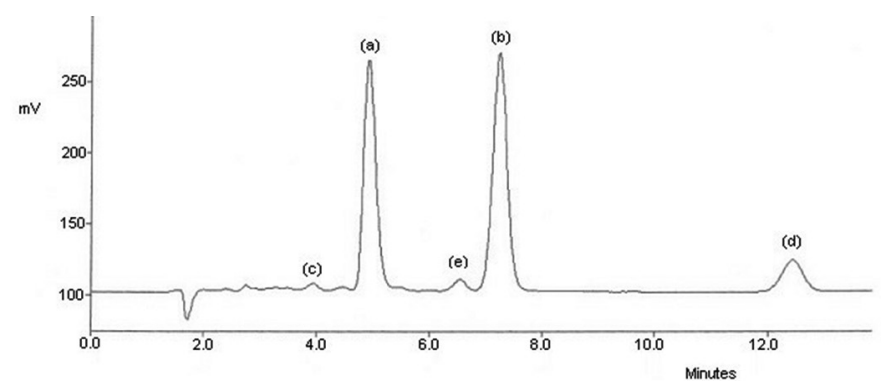

Figure. 4. Representative chromatogram of ramipril under acidic stress: ramipril (a), cloxacillin sodium (b), ramiprilat (c), ramipril diketopiperazine (d), other degradation product (e). $1 \mathrm{mV}: 0.001 \mathrm{AU}$.

\section{b) Oxidation:}

Ramipril was degraded under oxidative stress at room temperature and at $80{ }^{\circ} \mathrm{C}$. After $6 \mathrm{~h}$. of oxidation at $80^{\circ} \mathrm{C}$ the percentage of ramipril degradation was $23.4 \%$. It was observed the formation of a degradation product with that appeared at the same retention time that the alkaline degradation product, therefore probably it corresponds to ramiprilat, and a degradation product identified as ramipril diketopiperazine. Since the degradation products are the same that in the hydrolysis reaction, probably the samples are hydrolyzed due to the conditions of the reaction. This can be observed in Fig. 5

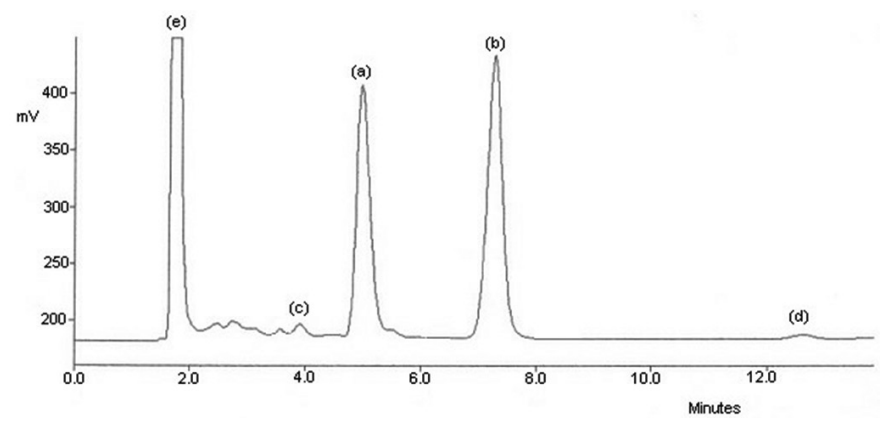

Figure. 5. Representative chromatogram of ramipril under oxidative stress: ramipril (a), cloxacillin sodium (b), ramiprilat (c), ramipril diketopiperazine (d), blank sample (e). $1 \mathrm{mV}: 0.001 \mathrm{AU}$.

c) Thermal degradation:

Stress by heat produced a $15.1 \%$ of ramipril degradation with the formation of ramipril diketopiperazine as the principal degradation product. This can be observed in Fig. 6. This is in agreement with results obtained by B. Hogan ${ }^{7}$, and is different with the work of K. Patil ${ }^{5}$ who reported that the drug was stable to thermal degradation, but the stress was for less time.

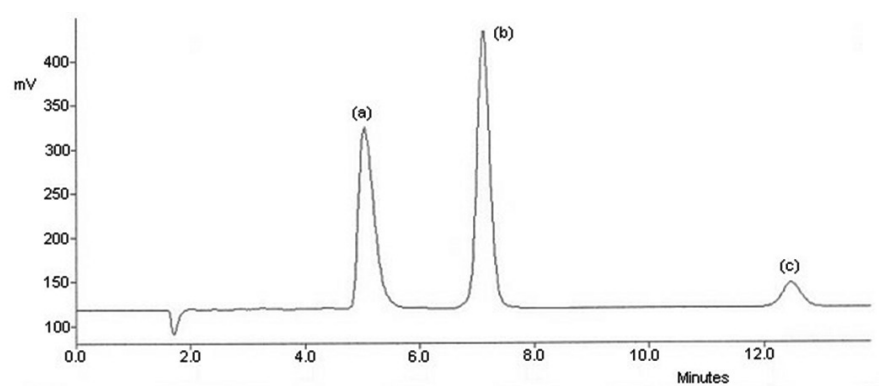

Figure. 6. Representative chromatogram of ramipril under thermal degradation: ramipril (a), cloxacillin sodium (b), ramipril diketopiperazine (c). $1 \mathrm{mV}$ : $0.001 \mathrm{AU}$.

d) Photostability:

Ramipril solution and solid state was stable to UV and VIS radiation. This is in accordance with previous work ${ }^{4,5}$ who evaluated the stability of ramipril 
under UV radiation, but not under VIS radiation

\section{Application to tablets of ramipril}

This method was used for the quantification of two commercial products of ramipril tablets $2,5 \mathrm{mg}$. The percentage of ramipril was found to be $98,6 \pm 2,2 \%$ and $96,7 \% \pm 4.8 \%($ mean $\pm S D, n=6)$ for manufacturer $A$ and $B$ respectively. In the chromatograms of the tablets from manufacturer B, it was observed the appearance of ramipril diketopiperazine.

\section{CONCLUSIONS}

A simple stability-indicating LC method for determination of ramipril in the presence of its degradation products has been developed and validated. The method has the required linearity, precision, accuracy, selectivity, robustness, DL and QL necessary for the quantitative determination of ramipril in drug substance and tablets. Thus the developed method can be used for quality control and for stability studies.

The results obtained from the stress testing show that ramipril drug substance is particularly unstable under alkaline conditions. The drug is also unstable under acidic and neutral hydrolysis, oxidation and thermal degradation. Therefore, care should be taken in the manufacturing process and during storage of this product in order to avoid degradation, because if the drug is degraded could result in diminution of the therapeutic activity and safety.

\section{ACKNOWLEDGEMENT}

This work was supported by research project DIUC 208.074.039-1.0, Research Department, University of Concepción.

\section{REFERENCES}

[1] International Conference on Harmonization, ICH Q1 A (R2), Stability Testing of New Drug Substances and Products, 2003.

[2] S. Baertschi. Pharmaceutical Stress Testing, Predicting Drug Degradation, Taylor \& Francis Group, Boca Raton, 2005, pp. 13-28.

[3] G. K. Mc Evoy. AHFS Drug Information, American Society of HealthSystem Pharmacists, Bethesda, 2009, pp 2016-2019.

[4] A. Elshanawane, S. Mostafa, M. Elgawish, Chromatogr. 67, 567, (2008)

[5] K. patil, V. Rane, J. Sangshetti, D. Shinde, Chromatogr. 67, 575, (2008)

[6] F. Belal, I. Al-Zaagi, E. Gadkariem, M. Abounassif, J. Pharm. Biomed. Anal. 24, 335, (2001)

[7] B. Hogan, M. Williams, A. Idiculla, T. Veysoglu, E. Parente, J. Pharm. Biomed. Anal. 23, 637, (2000)

[8] L. Hanysova, M. Vaclavkova, J. Dohnal, J. Klimes, J. Pharm. Biomed. Anal. 37, 1179, (2005)

[9] L. Allen, M. stiles, S. Prince, H. McLaury, M. Sylvestri, Am. J. Health Syst. Pharm. 52, 2433, (1995)

[10] D. Angeli, C. Trezza. Clin. Drug. Invest. 29, 667, (2009)

[11] X. Lu, J. Shen-Tu, J. Liu, J. Pharm. Biomed. Anal. 13, 478, (2006)

[12] Z. Zhu, A. Vachareau, L. Neirinck, J. Chromatogr. B. Analyt. Biomed. Life Sci. 5, 297,. (2002)

[13] International Conference on Harmonization, ICH Q2B, Validation of Analytical Procedures, Methodology, 1996.

[14] S. Baertschi. Pharmaceutical Stress Testing, Predicting Drug Degradation, Taylor \& Francis Group, Boca Raton, 2005, pp. 141-150. 